\title{
Cyclin D1b represses breast cancer cell growth by antagonizing the action of cyclin D1a on estrogen receptor $\alpha$-mediated transcription
}

\author{
JING ZHU ${ }^{1,3}$, SUBRATA SEN ${ }^{2}$, CHONGJUAN WEI ${ }^{1}$ and MARSHA L. FRAZIER ${ }^{1}$ \\ ${ }^{1}$ Department of Epidemiology, The University of Texas M.D. Anderson Cancer Center, 1155 Pressler Street; \\ ${ }^{2}$ Department of Molecular Pathology, The University of Texas M.D. Anderson Cancer Center, \\ 7450 Fannin Street, Houston, TX 77030, USA
}

Received July 22, 2009; Accepted September 7, 2009

DOI: 10.3892/ijo_00000473

\begin{abstract}
Alternate splicing of the cyclin D1 gene gives rise to transcripts $\mathrm{a}$ and $\mathrm{b}$ which encode two protein isoforms cyclin D1a and cyclin D1b. Cyclin D1a can substitute for estrogen to activate estrogen receptor $\alpha$ - $(\mathrm{ER} \alpha)$ mediated transcription and can induce the proliferation of estrogen responsive tissues. However, little is known about the biological role of cyclin D1b in transcriptional regulation. In this study, we determined that cyclin D1b is incapable of inducing ER $\alpha$-mediated transcription because it fails to recruit steroid receptor coactivator-1 (SRC-1) to ER $\alpha$. Moreover, cyclin D1b antagonizes cyclin D1a-induced ER $\alpha$-mediated transcription by competing with cyclin D1a for ER $\alpha$ binding. Cell proliferation assay showed that cyclin D1b repressed the ER $\alpha$ positive breast cancer T47D cell growth. Our findings suggest that the cyclin D1b represses breast cancer cell growth by antagonizing the action of cyclin D1a on ER $\alpha$-mediated transcription.
\end{abstract}

\section{Introduction}

Cyclin D1 is known as a proto-oncogene that was first identified in human parathyroid adenoma (1). Alternate splicing of cyclin D1 gene gives rise to a variant transcript which encode a variant cyclin D1 isoform termed cyclin D1b $(2,3)$. Cyclin D1b shares the same cyclin box and pRBbinding domain with conventional cyclin D1a, but lacks the

Correspondence to: Dr Marsha L. Frazier, Department of Epidemiology, The University of Texas, M.D. Anderson Cancer Center, 1155 Pressler Street, Houston, TX 77030, USA

E-mail:mlfrazier@mdanderson.org

Present address: ${ }^{3}$ Department of Neuroscience, Johns Hopkins University School of Medicine, 855 N. Wolfe Street, Baltimore, MD 21205, USA

Key words: cyclin D1b, breast cancer, estrogen receptor $\alpha$, transcriptional regulation last 55 amino acids of the carboxyl terminus, which was replaced by a 33 amino acid sequence unique to cyclin D1b. The carboxyl terminus of cyclin D1a contains a PEST rich motif and threonine residues that control the protein nuclear export and turnover. Unexpectedly, despite the fact that cyclin D1b lacks PEST motif and the threonine residues, the half-life of cyclin D1a and cyclin D1b was indistinguishable and cyclin D1b did not accumulate to higher levels under the conditions examined (4-6).

The function of cyclin D1a has been widely studied. In response to mitogenic stimulation, it binds and activates the cyclin-dependent kinases CDK4 and CDK6, which phosphorylate their downstream target, the retinoblastoma protein $\mathrm{Rb}$ and then induce cell cycle progression (7). Unlike cyclin D1a, the findings on the roles of cyclin D1b in cell cycle regulation have been inconsistent. Some studies showed that cyclin D1b is capable of associating with CDK4 but the complex is compromised in its ability for RB phosphorylation $(4,6)$, while $\mathrm{Lu}$ et al reported that cyclin D1b-CDK4 complex can phosphorylate RB (5). Besides the canonical cell cycle regulation, accumulating evidence indicates that cyclin D1a associates with a number of transcription factors and transcriptional coregulators to modulate their activities independent of CDKs. It has been reported that cyclin D1a can regulate several transcriptional factors: SP1 (8), STAT3 (9), DMP1 (10) and members of the nuclear receptor superfamily including the estrogen receptor ER (11-13), androgen receptor AR $(14,15)$, thyroid hormone receptor TR (16) and transcriptional coregulators such as P/CAF $(17,18)$, NcoA/SRC1 (19), AIB-1 (19), GRIP-1 (20), HDACs (16) and TAF250 (21). Zwijsen et al first reported that cyclin D1a could substitute for estrogen in activating ER $\alpha$-mediated transcription and contributes to potentiation of estrogeninduced cell proliferation in estrogen-responsive tissue such as breast epithelium (11). When ER $\alpha$ is activated by estrogen, a conformational change exposes activation function domain-2 (AF-2) that constitutes a binding site for steroid receptor coactivator-1 (SRC-1). SRC-1 recruitment to ER $\alpha$ potentiates binding of the receptor to estrogen responsive element (ERE), triggering target gene transcription. The carboxyl terminal leucine-rich LLXXXL motif at position 254-259 of cyclin D1a is very similar to the AF2 domain of ER $\alpha$. In the 
absence of hormone, cyclin D1a can act as a bridging factor to recruit SRC-1 to ER $\alpha$ and activate ER $\alpha$-mediated transcription. In the presence of estrogen, cyclin D1a can enhance ER $\alpha$ mediated transcription $(11,12,19)$. However, little is known about the biological role of cyclin D1b in transcriptional regulation.

Here we examined the ability of cyclin D1b to induce ER $\alpha$-mediated transcription as has been seen with cyclin D1a. By transcriptional assays and a series of in vivo and in vitro binding assays, we found that cyclin D1b is incapable of inducing $\mathrm{ER} \alpha$-mediated transcription because it fails to recruit SRC-1 to ER $\alpha$. Moreover, cyclin D1b antagonizes cyclin D1a-induced ER $\alpha$-mediated transcription by competing with cyclin D1a for ER $\alpha$ binding. Cell proliferation assay showed that cyclin D1a and cyclin D1b have differential effects on estrogen-dependent breast cancer cell growth.

\section{Materials and methods}

Cell culture. Human breast cancer cell lines MCF7 and T47D, human colorectal cancer cell HCT-15 cells, human osteosarcoma cell U2-OS and human embryonic kidney cell HEK293 cells were maintained in DMEM/F-12 supplemented with $10 \% \mathrm{FBS}, 2 \mathrm{mmol} / \mathrm{l} \mathrm{L}$-glutamine, $100 \mathrm{U} / \mathrm{ml}$ penicillin, and $100 \mu \mathrm{g} / \mathrm{ml}$ streptomycin in humidified atmosphere containing $5 \% \mathrm{CO}_{2}$ at $37^{\circ} \mathrm{C}$. For estrogen-free conditions, phenol red-free media was used supplemented with charcoal dextran/treated fetal bovine serum (Hyclone, Logan, Utah).

Plasmids and transfection. The cyclin D1a (IMAGE ID 3508088), ER $\alpha$ (IMAGE ID 40128595) and SRC-1 (IMAGE ID 40027438) cDNA clones were obtained from the Mammalian Gene Collection. The cyclin D1b cDNA was generated from the human colorectal cancer cell line HCT-15 and PCR products of the cDNA were cloned into the TA cloning vector (Invitrogen, Carlsbad, CA). The cDNA clones were sequenced and compared with the published sequence to ensure their identity (3). The cyclin D1a, cyclin D1b, ER $\alpha$ and SRC-1 cDNAs described above were digested from their vectors and cloned into the mammalian expression vector pcDNA3 (Invitrogen). Myc-tagged ER $\alpha$ and SRC-1 were generated by adding a Myc tag to ER $\alpha$ and SRC- 1 cDNA by PCR and then the product was sub-cloned into the pcDNA3 expression vector. The glutathione S-transferase fused ER $\alpha$ (GST-ER $\alpha$ ) and SRC-1 (GST-SRC1) expression plasmids were generated by digesting ER $\alpha$ and SRC-1 fragments from their expression plasmids, then inserting into the GST fusion vector pGEX-5X-3 (GE Healthcare Life Sciences, Pittsburgh, PA). The reporter plasmid ERE-TK-CAT has been previously described (22) and was kindly provided by Dr Ming-Jer Tsai (Baylor College of Medicine, Houston, TX). DNA was transiently transfected into the cells using Lipofectamine 2000 (Invitrogen). Twenty-four hours before transfection, cells were maintained in estrogen-free media as mentioned above. Four hours after transfection, cells were fed with fresh media and $10 \mathrm{nM} \mathrm{17ß-estradiol} \mathrm{(Sigma-}$ Aldrich, St. Louis, MO). pCMV-LacZ plasmid (Invitrogen) was used as an internal control to assess the transfection efficiency.
Stable transfection through retroviral vector. We cloned the cDNAs for cyclin D1a and cyclin D1b into retroviral pCL vector. The pCL clones were transfected into HEK293 cells by using a modification of the HEPES-buffered saline calcium phosphate method (23). The medium was replaced $18 \mathrm{~h}$ after transfection. Recombinant retrovirus supernatants were collected after 2 days and filtered through a $0.45-\mu \mathrm{m}$ poresize filter (Millipore, Billerica, MA), and used to infect human breast adenocarcinoma cells T47D in culture. Two days after infection they were placed under G418 selection $(800 \mathrm{mg} / \mathrm{ml})$ and grown for 10 days.

Transcriptional analysis. MCF7 and T47D cells were seeded in $60-\mathrm{mm}$ diameter tissue culture dishes in estrogen-free media as indicated above and were cotransfected with $5 \mu \mathrm{g}$ cyclin D1a or cyclin D1b expression plasmid or empty vector together with $2.5 \mu \mathrm{g}$ ERE-TK-CAT reporter plasmid and $0.5 \mu \mathrm{g}$ pCMV-LacZ plasmid. U2-OS was cotransfected with $1 \mu \mathrm{g}$ cyclin D1a or cyclin D1b expression plasmid or empty vector together with $0.4 \mu \mathrm{g}$ ER $\alpha$ expression plasmid, $2.5 \mu \mathrm{g}$ ERE-TK-CAT reporter plasmid and $0.1 \mu \mathrm{g}$ pCMV-LacZ plasmid per $60-\mathrm{mm}$ diameter tissue culture dish. After transfection, cells were fed with fresh media and $10 \mathrm{nM} 173$-estradiol (Sigma-Aldrich). After $24 \mathrm{~h}$ stimulation, cells were rinsed with cold PBS, harvested and resuspended in lysis buffer, and assayed for chloramphenicol acetyltransferase (CAT) and $\beta$-galactosidase ( $(-\mathrm{Gal}$ ) levels (Roche Applied Science, Indianapolis, IN, CAT and B-Gal ELISA assay kit). The CAT levels were normalized by $\beta$-Gal levels for transfection efficiency control. The data represent the average and standard deviation of independent experiments. The Student's t-test was used to compare the relative CAT level in cyclin D1a, cyclin D1b and empty vector-transfected cells.

Immunoprecipitation and Western blot. Cells were rinsed with cold PBS, harvested and resuspended in lysis buffer [20mM Tris ( $\mathrm{pH} 8.0$ ), $137 \mathrm{mM} \mathrm{NaCl}, 2 \mathrm{mM}$ EDTA, 10\% Glycerol, $1 \%$ NP-40, Halt ${ }^{\mathrm{TM}}$ protease inhibitor cocktail (Pierce Biotechnology, Rockford, IL)]. Extracts were cleared by centrifugation and further precleared by rocking at $4{ }^{\circ} \mathrm{C}$ with washed protein G-Sepharose beads (Pierce Biotechnology). Precleared extracts were immunoprecipitated with c-Myc antibody (Clontech Laboratories, Mountain View, CA) or ER $\alpha$ antibody (Dako Cytomation, Carpinteria, CA) and protein $\mathrm{G}$-sepharose beads at $4^{\circ} \mathrm{C}$ overnight. Sepharose beads were washed five times with lysis buffer and boiled in Laemmli buffer (Bio-Rad Laboratories, Hercules, CA) for $5 \mathrm{~min}$, and released proteins were detected with antibodies against cyclin D1 (DCS-6, Lab Vision Corporation, Fremont, CA), cyclin D1b (GN3999), ER $\alpha$ (Dako Cytomation). The DCS-6 antibody reacts with both cyclin D1a and b. The GN3999 antibody was generated in a rabbit injected with a cyclin D1b specific peptide 'LVPRKCRGWCQGPQG' linked to keyhole limpet protein (Sigma Genosys).

In vitro binding assay. In vitro binding assays (pull-down assays) were performed as previously described (24). GST$\mathrm{ER} \alpha$ and GST-SRC1 were prepared in Escherichia coli BL21 cells. In vitro-translated cyclin D1a, cyclin D1b and ER $\alpha$ 
A
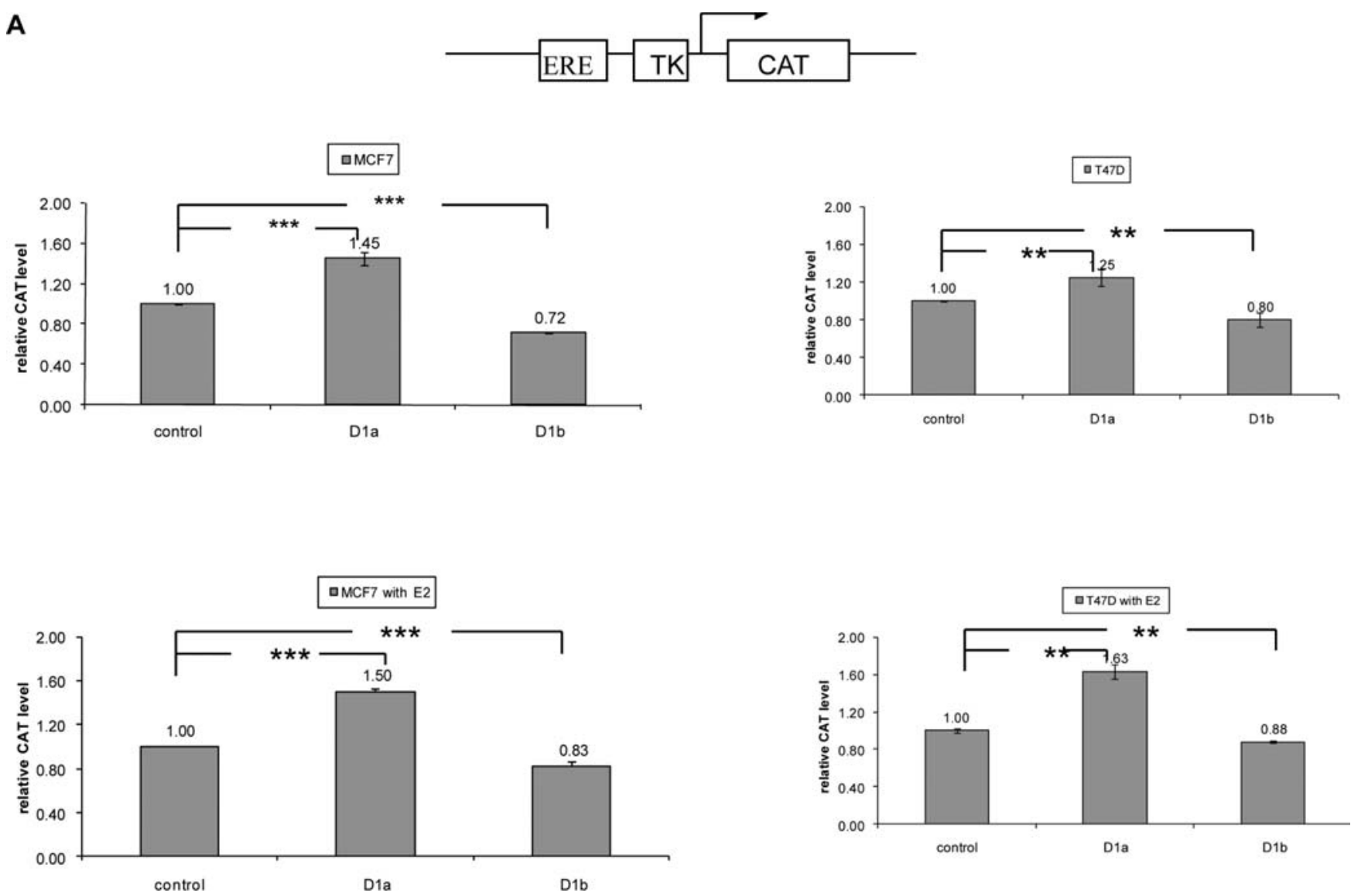

B
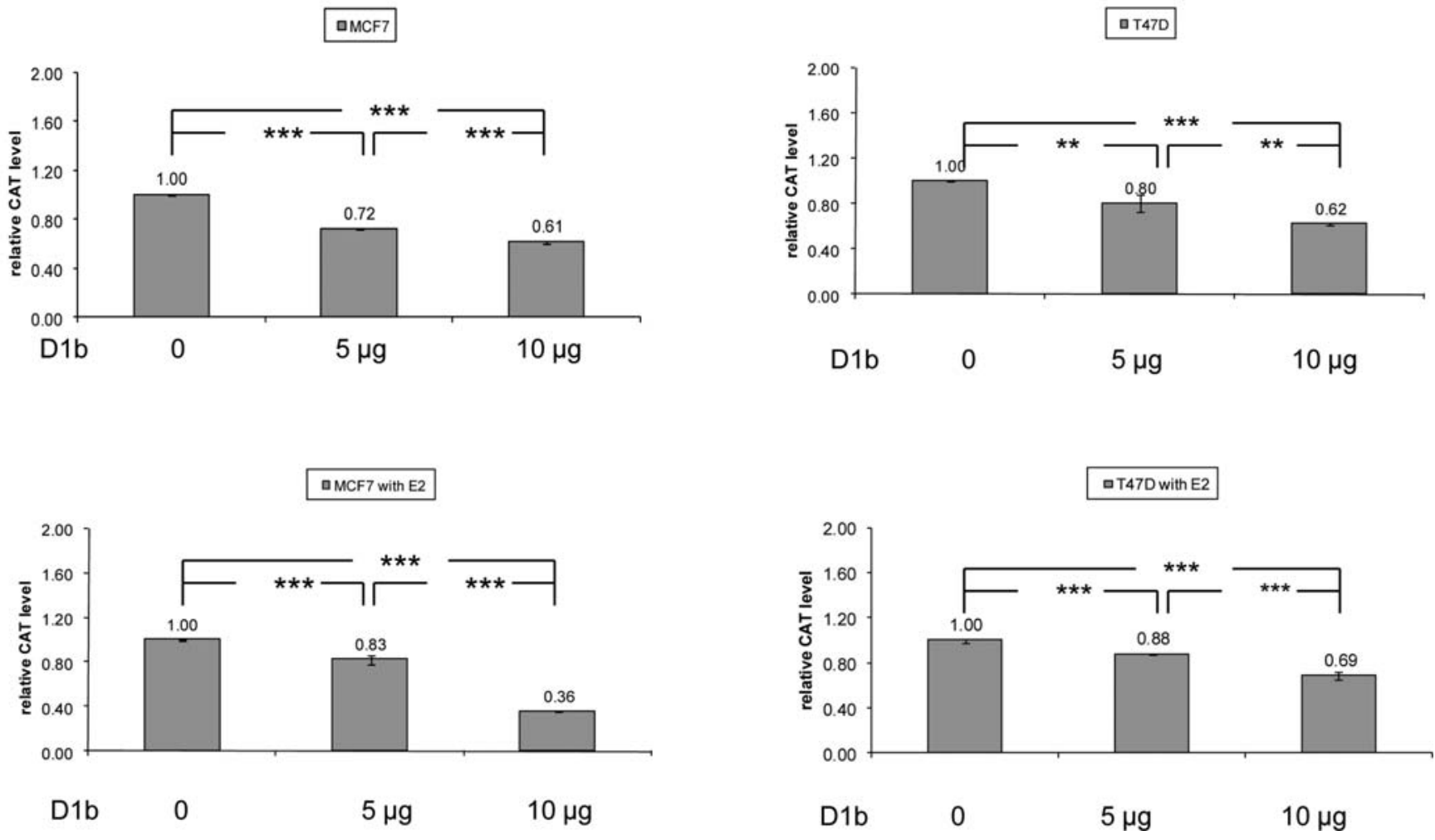

Figure 1. Cyclin D1b is incapable of inducing ER $\alpha$-mediated transcription. (A) Cyclin D1a or cyclin D1b expression plasmid was transiently trans-fected in ER $\alpha$-positive breast cancer cell lines MCF-7 and T47D together with an ERE-TK-CAT reporter plasmid and pCMV-LacZ plasmid which served as an internal control. This was done in the presence or absence of 17B-estradiol. The relative CAT levels were calculated by normalizing to the B-Gal levels and dividing by the CAT levels in empty vector-transfected cells. D1a: cyclin D1a $5 \mu \mathrm{g}$, D1b: cyclin D1b $5 \mu \mathrm{g}$, control: empty vector $5 \mu \mathrm{g}$, E2: $10 \mathrm{nM} 17 ß$-estradiol. $\left({ }^{* * *} \mathrm{p}<0.001 ;{ }^{* *} \mathrm{p}<0.01\right)$. (B) The repressive effect of cyclin D1b on ERE responsive transcription is dose dependent. MCF7 and T47D cells were transiently transfected with increasing amount of cyclin D1b $(0,5$ and $10 \mu \mathrm{g})$, together with ERE-TK-CAT and pCMV-LacZ constructs. The relative CAT levels were calculated by normalizing to the B-Gal level and dividing by the CAT level in empty vector-transfected cells. E2: 17ß-estradiol (10 nM). 


\section{C}

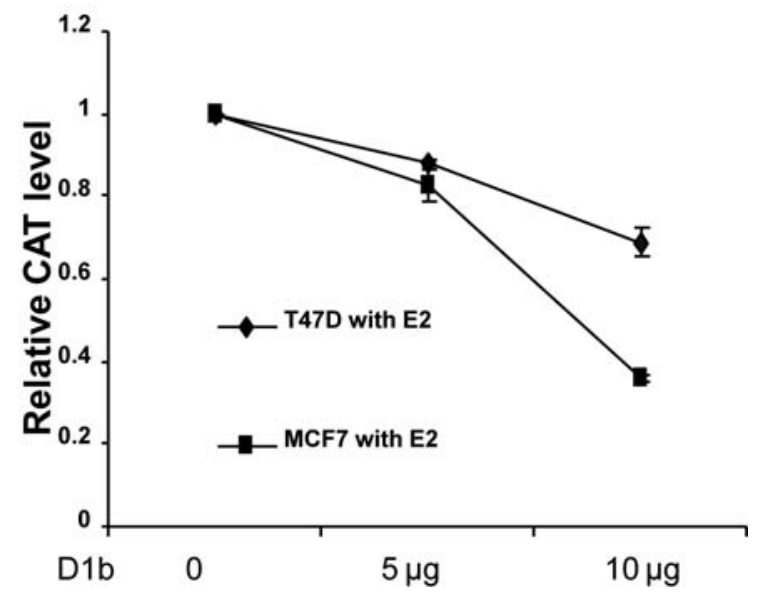

Figure 1. (C) MCF7 and T47D cells were cotransfected with increasing amount $(0,5$ and $10 \mu \mathrm{g})$ of cyclin D1b expression vectors together with ERE-TK-CAT and pCMV-LacZ constructs. Transfection of cyclin D1b in MCF7 cells, which express higher levels of endogenous cyclin D1a, results in greater decrease of ERE-responsive CAT transcription compared to T47D cells in the presence of $10 \mathrm{nM}$ 17ß-estradiol. The relative CAT level in the absence of cyclin D1b was set as 1 .

proteins were prepared by coupled transcription-translation with a TNT-coupled reticulocyte lysate kit (Promega Corporation, Madison, WI) using $1 \mu \mathrm{g}$ of expression plasmid DNA in a total volume of $50 \mu 1$, respectively. In vitrotranslated proteins were added to GST-ER $\alpha$ or GST-SRC1 fusion protein bound to Glutathione-sepharose beads in binding buffer [20 mM Tris $\mathrm{pH} 7.5,50 \mathrm{mM} \mathrm{NaCl}, 10 \%$ glycerol, 1\% NP-40, Halt protease inhibitor cocktail (Pierce Biotechnology)] and rotated for $1 \mathrm{~h}$ at room temperature. Sepharose beads were washed five times with binding buffer and bound proteins were eluted by boiling for $5 \mathrm{~min}$ in Laemmli buffer and separated on $10 \%$ SDS-PAGE gels. The proteins binding to GST-ER $\alpha$ and GST-SRC1 were detected by Western blot analysis using antibodies directed against cyclin D1a and cyclin D1b (DCS-6). For testing a ternary complex, in vitro-translated ER $\alpha$ and cyclin D1a or cyclin D1b were added to GST-SRC1 in the presence or absence of $1 \mu \mathrm{M} 17 ß$-estradiol using similar conditions as described above. For the Western blot analysis, cyclin D1 (DCS-6) and $\mathrm{ER} \alpha$ antibodies were used.

Protein competition assay. Both in vitro and in vivo assays were performed to assess the protein competition between cyclin D1a and cyclin D1b for ER binding. In the in vitro assay, in vitro-translated cyclin D1b protein was preincubated with GST-ER $\alpha$ for $30 \mathrm{~min}$ at room temperature then in vitro-translated cyclin D1a protein was added into this mixture and incubated for another $30 \mathrm{~min}$ at room temperature. The GST pull-down assays as described above were next conducted.

For the in vivo assay, increasing amounts of cyclin D1b expression plasmid were cotransfected with a fixed amount of cyclin D1a and Myc-ER $\alpha$ expression plasmids into HEK293 cells. Immunoprecipitation was performed as described above.
Cell proliferation assay. Cells in log-phase growth were seeded $\left(3-4 \times 10^{4}\right.$ cells/well) into six-well plates in triplicate and allowed to adhere overnight. Cells were detached with $0.25 \%$ trypsin$0.02 \%$ EDTA after 24, 48 and $72 \mathrm{~h}$, and counted in duplicate in the presence of trypan blue dye using a haemocytometer.

Statistical analysis. Statistical differences were calculated by Student's t-test. Difference were considered significant at $\mathrm{P}<0.05$.

\section{Results}

Cyclin D1b is incapable of inducing ERa-mediated transcription. To investigate the effect of cyclin D1b on $\operatorname{ER} \alpha-$ mediated transcription, ERE-TK-CAT, a chloramphenicol acetyltransferase (CAT) reporter construct was employed (22). This construct carries an upstream estrogen responsive element (ERE). We transfected the ER-positive breast cancer cell lines MCF7 and T47D with the cyclin D1a or cyclin D1b expression plasmids together with ERE-TK-CAT reporter plasmid and pCMV-LacZ construct as a transfection efficiency control. Consistent with previous studies (11), cyclin D1a activated ERE-responsive CAT transcription in the absence of $17 ß$-estradiol and enhanced the transcription in the presence of $17 ß$-estradiol $(10 \mathrm{nM})$ in both MCF7 and T47D cells (Fig. 1A). Surprisingly, we found that the relative CAT levels were lower in the cyclin D1b-transfected MCF7 and T47D cells than the CAT levels with the empty vectortransfected cells. This was the case in both the presence and absence of 17ß-estradiol (Fig. 1A). Next we examined the repressive effect of cyclin D1b on ERE-responsive transcription to determine if it is dose-dependent. When MCF7 and T47D cells were transfected with increasing amounts of cyclin D1b expression plasmid, we found that the relative CAT levels were decreased as the amount of cyclin D1b increased in both the presence and absence of 17ß-estradiol in MCF7 and T47D cells (Fig. 1B). The two breast cancer cell lines MCF7 and T47D both express endogenous wildtype ER $\alpha$ but MCF7 cells express relatively higher levels of endogenous cyclin D1a compared to T47D (19). Transfection of cyclin D1b into MCF7 results in greater repression of ER $\alpha$-mediated CAT transcription in the presence of $17 \beta$ estradiol than for T47D (Fig. 1C).

Cyclin DIb antagonizes the stimulatory effect of cyclin Dla on ER $\alpha$-mediated transcription. To confirm the effect of cyclin D1b on ER $\alpha$-mediated transcription, we cotransfected the human osteosarcoma cell line U2-OS, which has negligible levels of ER $\alpha$ (11), with cyclin D1a or cyclin D1b expression plasmid together with human ER $\alpha$ expression plasmid. Consistent with the results observed in MCF7 and T47D cells, cyclin D1b repressed ERE-responsive CAT transcription in ER $\alpha$-transfected U2-OS cells in the presence and absence of 17ß-estradiol (Fig. 2). Furthermore, we examined whether cyclin D1b affects the stimulatory effect of cyclin D1a on ER $\alpha$-mediated transcription. Equal amount of cyclin D1a and cyclin D1b expression plasmids, together with ER $\alpha$, ERE-TK-CAT and pCMV-LacZ constructs, were cotransfected into U2-OS cells. We found that the action of cyclin D1a on ER $\alpha$-mediated transcription was antagonized 

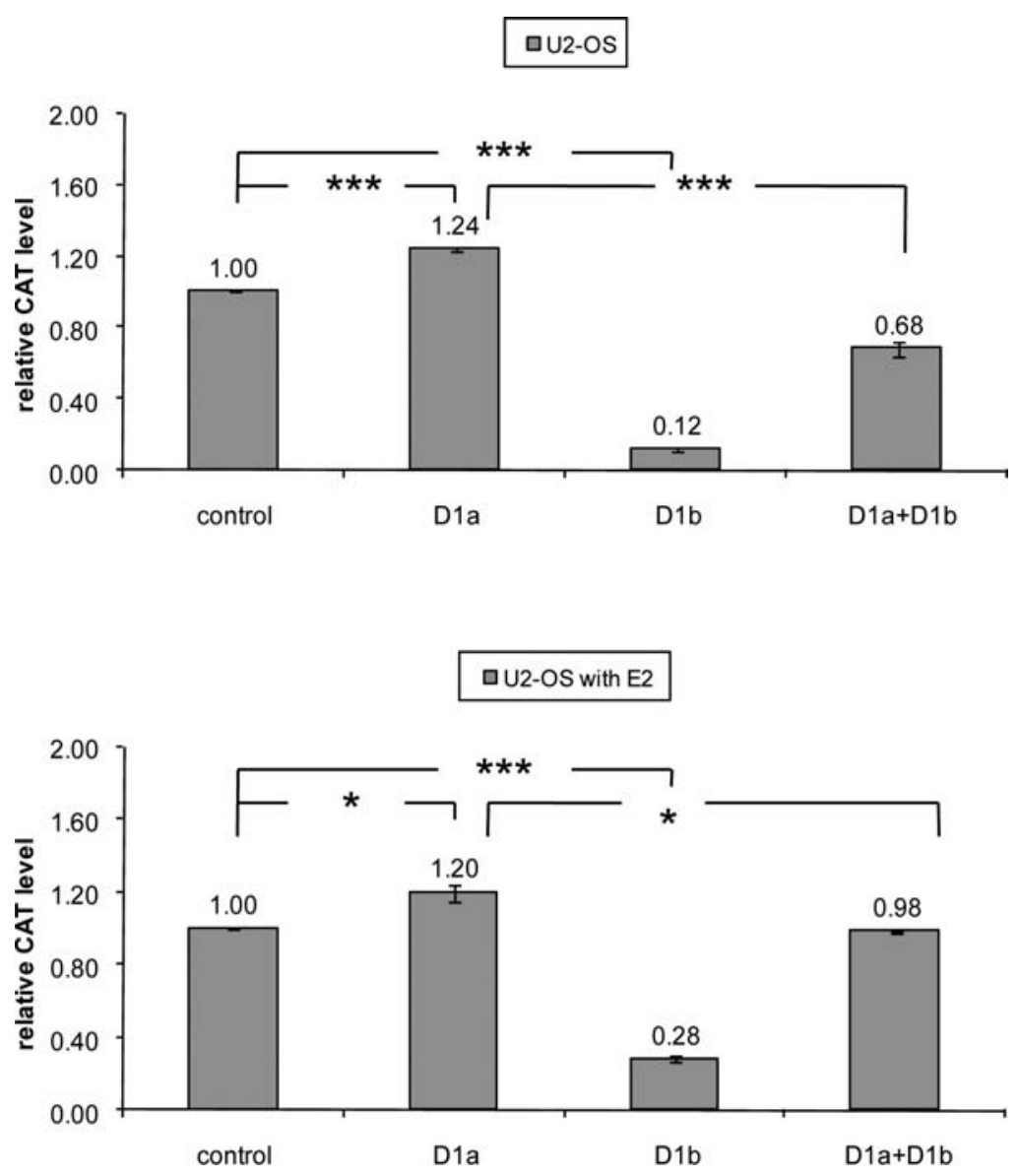

Figure 2. Cyclin D1b antagonizes the action of cyclin D1a on ERE-responsive transcription. Cyclin D1 expression plasmids were transfected in U2-OS cells together with ER $\alpha$, ERE-TK-CAT and pCMV-LacZ plasmids and then tested for transcription of the CAT report construct. The relative CAT levels were normalized to $\beta$-Gal levels and were divided by the CAT level in the empty vector-transfected cells. D1a: cyclin D1a $1 \mu \mathrm{g}$; D1b: cyclin D1b $1 \mu \mathrm{g}$; control: empty vector $1 \mu \mathrm{g}$; D1a+b: cyclin D1a $1 \mu \mathrm{g}+$ cyclin D1b $1 \mu \mathrm{g}$. E2: 17ß-estradiol $(10 \mathrm{nM}) .\left({ }^{* * *} \mathrm{p}<0.001 ;{ }^{*} \mathrm{p}<0.05\right)$.

by cyclin D1b. The relative CAT levels in cyclin D1a and cyclin D1b-cotransfected cells were significantly lower than that in cyclin D1a-transfected cells; moreover, this antagonizing effect is greater in the absence of $17 ß$-estradiol than in its presence (Fig. 2). In the presence of estrogen, cyclin D1a and estrogen synergistically activate ER $\alpha$-mediated transcription; however, in the absence of estrogen, cyclin D1a played a dominant role. This may explain why the antagonizing effect of cyclin D1b is greater in the absence of estrogen than in the presence of estrogen.

Cyclin D1b competes with cyclin Dla for ER $\alpha$-binding. We investigated the possible interaction between cyclin D1b and $\mathrm{ER} \alpha$ in the ER $\alpha$-positive breast cancer cell line T47D. Coimmunoprecipitation experiments revealed a physical association between endogenous ER $\alpha$ and cyclin D1b in T47D cells, and also confirmed the physical association of cyclin D1a and ER $\alpha$ (Fig. 3A). This association was confirmed in an ectopically expressing protein model. The cyclin D1a and cyclin D1b expression plasmids were cotransfected with the Myc-tagged ER $\alpha$ expression plasmid into ER-negative HEK293 cells, respectively. The immunoprecipitation assay showed that both cyclin D1a and cyclin D1b interact with
$\mathrm{ER} \alpha$ in vivo (Fig. 3B). To verify the in vivo binding assay results and test whether the interaction between cyclin D1b and $\mathrm{ER} \alpha$ is direct, an in vitro binding assay (GST-Pull-down assay) was employed. As shown in Fig. 3C, both cyclin D1a and cyclin D1b bind to GST-ER $\alpha$, but not to GST alone. This indicated that the binding between cyclin D1a or cyclin D1b with $\mathrm{ER} \alpha$ is direct and specific for $\mathrm{ER} \alpha$. Both in vivo and in vitro binding assays described above demonstrated that both cyclin D1a and cyclin D1b can bind to ER $\alpha$.

To investigate the possible mechanism by which cyclin D1b antagonizes cyclin D1a-induced ER $\alpha$-mediated transcription, we examined the binding capacity of cyclin D1a and cyclin D1b to ER $\alpha$. Increasing amounts of cyclin D1b expression plasmid were cotransfected with a fixed amount of cyclin D1a and Myc-tagged ER $\alpha$ expression plasmid into HEK293 cells. The immunoprecipitation assay showed that cotransfection of cyclin D1b reduced cyclin D1a association with ER $\alpha$ (Fig. 3D). The result was confirmed using an in vitro-binding study. In vitro-translated cyclin D1b was incubated with GST-ER $\alpha$, before cyclin D1a was added into the binding mix. Subsequent GST pull-down assays revealed that preincubation with cyclin D1b interfered with cyclin D1a binding to ER $\alpha$ (Fig. 3E). These results show that cyclin 
A

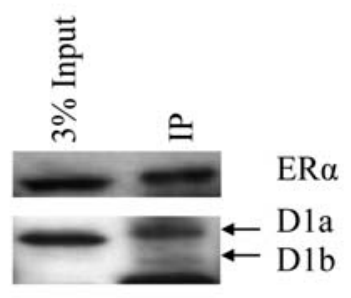

T47D

B

Myc-ER $\alpha$

D1a

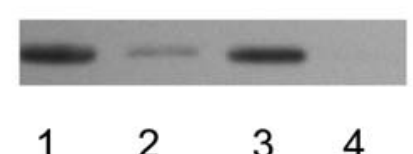

C

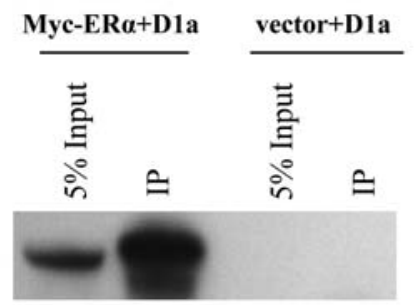

Myc-ER $\alpha$

D1b
1
3
4

$10 \%$ Input

D1a D1b

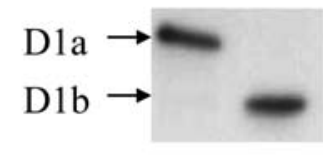

1

2
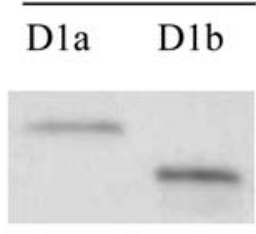

3
GST- ER $\alpha$
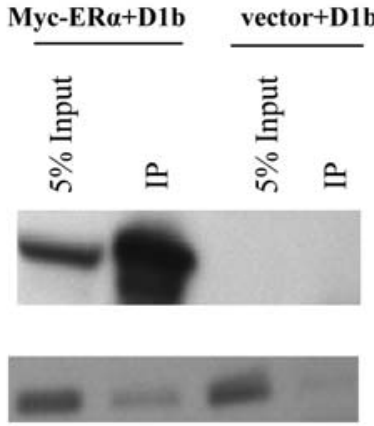

$\begin{array}{llll}5 & 6 & 7 & 8\end{array}$
D

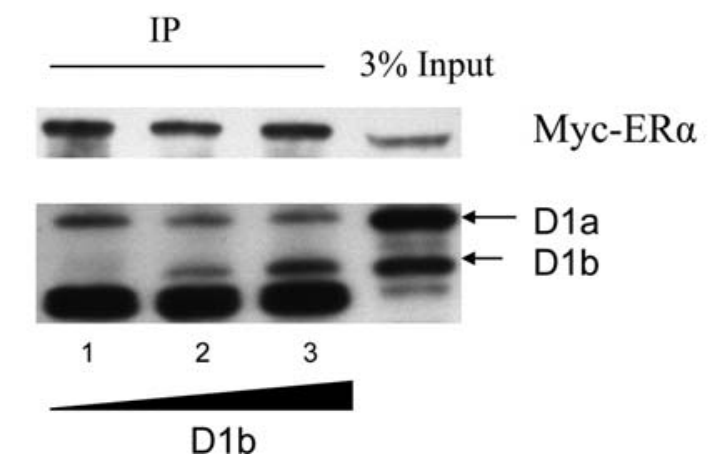

E

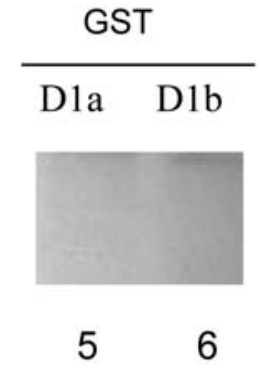

56

\section{GST- ERa}

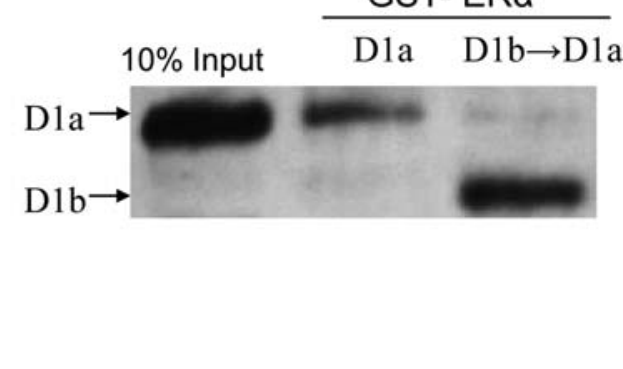

Figure 3. Cyclin D1b competes with cyclin D1a for ER $\alpha$ binding. (A) The cell lysate from T47D cells was immunoprecipitated with ER $\alpha$-specific antibody. The precipitated complexes were immunoblotted for cyclin D1a and cyclin D1b expression using anti-cyclin D1 monoclonal antibody (DCS-6). The upper panel shows ER $\alpha$, and the lower panel shows cyclin D1a, cyclin D1b and IgG light chain. (B) Cyclin D1a or cyclin D1b expression plasmid was transfected in HEK293 cells together with Myc-tagged ER $\alpha$ or empty vector and then immunoprecipitated using antibody against Myc-epitope tag. The Myc-ER $\alpha$ associated proteins were tested for cyclin D1a or cyclin D1b by Western blot analysis using anti-cyclin D1 monoclonal antibody (DCS-6). The upper panel shows Myc-tagged ER $\alpha$ and IgG heavy chains, and the lower panel shows cyclin D1a and cyclin D1b proteins. Lanes 1-4 display Myc-tagged ER $\alpha$ or empty vector-transfected cells in combination with cyclin D1a, and lanes 5-8 display Myc-tagged ER $\alpha$ or empty vector-transfected cells in combination with cyclin D1b. Lanes 1, 3, 5 and 7 display Myc-ER $\alpha$ and cyclin D1a or cyclin D1b input. (C) The in vitro interaction between cyclin D1 and ER $\alpha$. GST-ER $\alpha$ or control GST protein were immobilized on glutathione-agarose beads and mixed with in vitro-translated cyclin D1a or cyclin D1b to established in vitro binding. Cyclin D1a or cyclin D1b were tested by Western blot analysis using anti-cyclin D1 monoclonal antibody (DCS-6). Lanes 1 and 2 represent input, lanes 3 and 4 represent cyclin D1a and cyclin D1b bound to GST- ER $\alpha$, and lanes 5 and 6 represent GST control. (D) HEK293 cells were transfected with Myc-tagged ER $\alpha$, cyclin D1a and increasing amount of cyclin D1b $(0,2$ and $4 \mu \mathrm{g})$ expression plasmid. Twenty-four hours after transfection, cell were harvested, lysed and subjected to co-immunoprecipitation with anti-Myc antibody. The precipitated complexes were detected by immunoblotting with anti-cyclin D1 monoclonal antibody (DCS-6) and anti-ER $\alpha$ antibody. The upper panel shows Myc-tagged ER $\alpha$, and the lower panel shows cyclin D1a and cyclin D1b proteins and IgG light chains.1: D1a $2 \mu \mathrm{g}$, 2: D1a $2 \mu \mathrm{g}+\mathrm{D} 1 \mathrm{~b} 2 \mu \mathrm{g}$, 3: D1a $2 \mu \mathrm{g}+\mathrm{D} 1 \mathrm{~b} 4 \mu \mathrm{g}$. Input is refered to the cell lysate of condition 2. (E) In vitro-translated cyclin D1b was incubated with GST-ER $\alpha$ before cyclin D1a addition. Preincubation with cyclin D1b prevented cyclin D1a binding to GST-ER $\alpha$. 
A
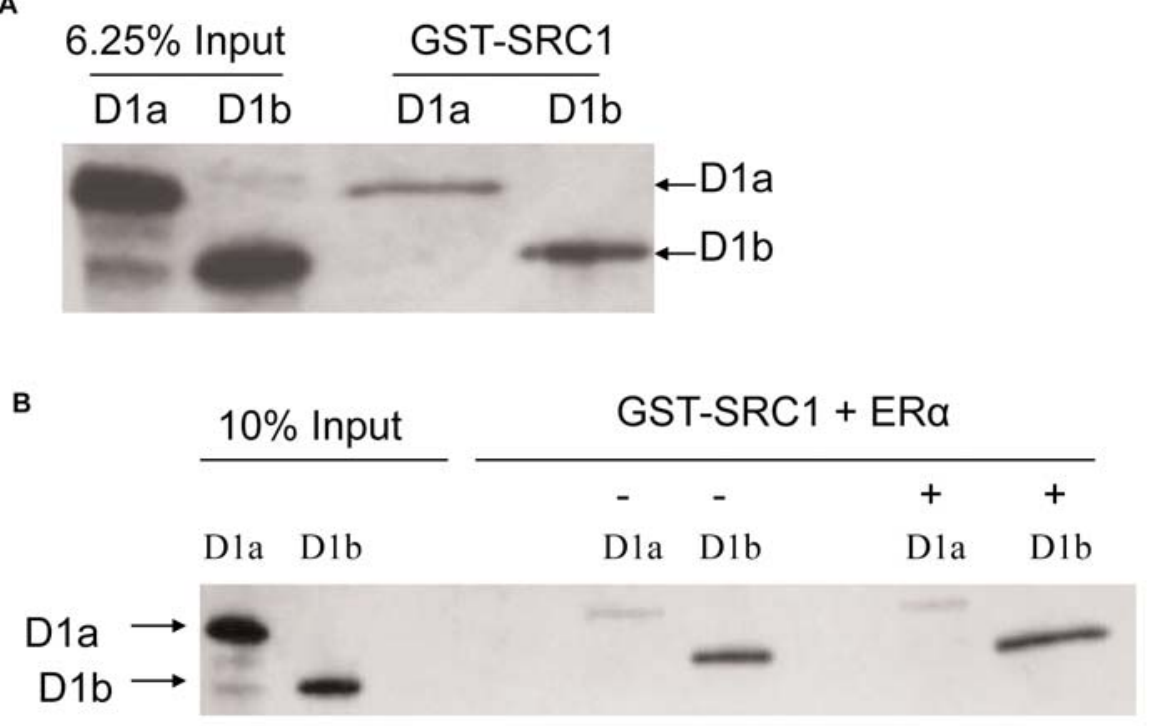

C

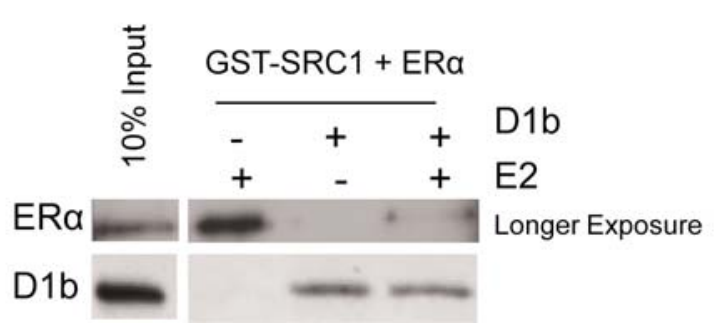

Figure 4. Cyclin D1b fails to recruit SRC-1 to ER $\alpha$. (A) The in vitro interaction between cyclin D1 and SRC-1. GST-SRC1 were immobilized on glutathionesepharose beads and mixed with in vitro-translated cyclin D1a or cyclin D1b. Cyclin D1a or cyclin D1b were detected by Western blot analysis using anticyclin D1 monoclonal antibody (DCS-6). (B and C) The GST-SRC1, ER $\alpha$ and cyclin D1 were tested for in vitro binding in GST pull-down assay. in vitrotranslated cyclin D1a or cyclin D1b and ER $\alpha$ were incubated with GST-SRC1 in the presence or absence of $1 \mu \mathrm{M} 17 ß$-estradiol and binding was detected by Western blot analysis using anti-cyclin D1 and anti-ER $\alpha$ monoclonal antibodies.

D1b has the ability to compete with cyclin D1a for association with $\mathrm{ER} \alpha$, providing one potential mechanism for antagonism.

Cyclin D1b fails to recruit SRC-1 to ERa. To investigate whether cyclin D1b can act as a bridging factor between ER $\alpha$ and SRC-1 similar to cyclin D1a, we tested the association of cyclin D1b, ER $\alpha$ and SRC-1. First, we tested if cyclin D1b can physically interact with SRC-1. As shown in Fig. 4A, both cyclin D1a and cyclin D1b can bind to GST-SRC1. To test whether a cyclin D1b-ER $\alpha$-SRC1 ternary complex can be formed, bacterially expressed GST-SRC1, and in vitrotranslated cyclin D1 and ER $\alpha$ were employed in an in vitro GST pull-down assay. We found that both cyclin D1a and cyclin D1b were pulled down by GST-SRC1 in the presence of ER $\alpha$ irrespective of the presence of estrogen (Fig. 4B). However, ER $\alpha$ binds to GST-SRC1 in an estrogen-dependent manner in vitro (Fig. 4C). ER $\alpha$ could not be pulled down by GST-SRC1 in the presence of cyclin D1b alone. This is distinct from cyclin D1a that could recruit ER $\alpha$ to GSTSRC1 in the absence of ligand (19). Less ER $\alpha$ was pulled down in the presence of both estrogen and cyclin D1b compared to the presence of estrogen alone (Fig. 4C). The data indicate that, although cyclin D1b could physically interact with both ER $\alpha$ and SRC-1, respectively, cyclin D1b could not recruit ER $\alpha$ to SRC-1 in the absence of estrogen and it fails to act as a ligand-independent adaptor molecule between ER $\alpha$ and its coactivator SRC-1.

Cyclin D1b represses estrogen responsive breast cancer cell proliferation. Estrogen receptor activity is required for proliferation of estrogen-responsive breast cells and early breast carcinogenesis. To define the functional action of cyclin D1a and cyclin D1b on ER $\alpha$-mediated transcription, we investigated the effect of cyclin D1a and cyclin D1b on estrogen-responsive breast carcinoma cell growth. Breast carcinoma T47D cells, which express wild-type endogenous $\mathrm{ER} \alpha$, were infected with the retrovirus encoding cyclin D1a and cyclin D1b and then tested for cell proliferation via direct cell counting. As shown in Fig. 5, overexpression of cyclin D1a significantly accelerated the proliferation of T47D (107.04, 164.23 and 173.47\%) compared with control on three consecutive days; however, cyclin D1b significantly repressed the proliferation in these cells $(76.40,78.91$ and $73.28 \%)$ as compared with control on three consecutive days. These data suggest that cyclin D1a and cyclin D1b have differential effects on estrogen-dependent breast carcinoma growth. Cyclin D1b expression may render specific growth inhibition in ER-positive breast carcinoma cells. 


\section{growth curve}

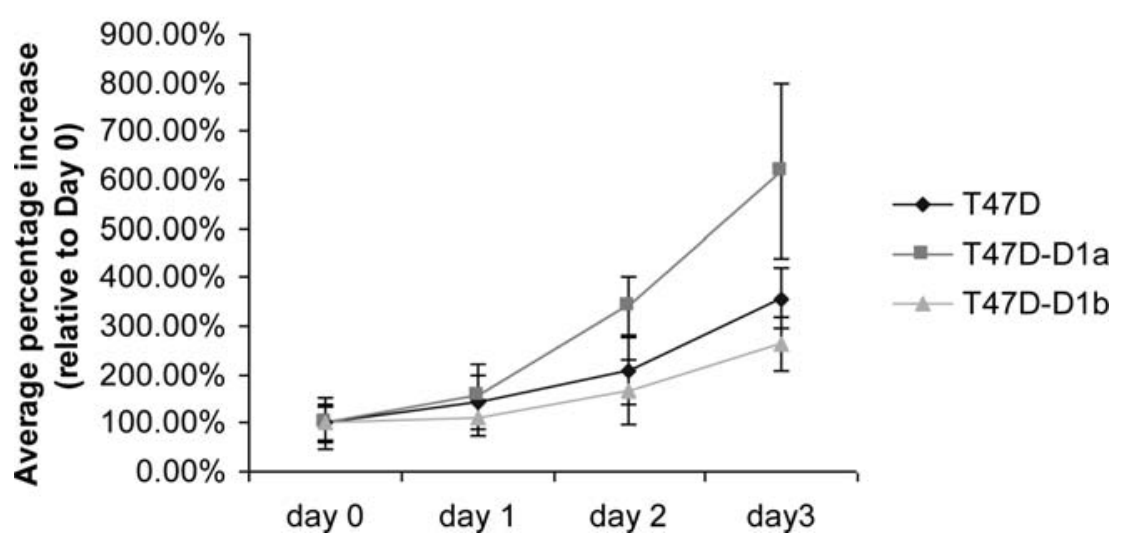

Figure 5. Cyclin D1b repressed breast cancer cell T47D cell proliferation. T47D cells were infected with retrovirus encoding cyclin D1a and cyclin D1b. Cell proliferation rate is determined by cell number increase on three consecutive days. The average percentage increase was calibrated by the cell numbers on day 0 . The data represent the average and standard deviation of independent experiments.
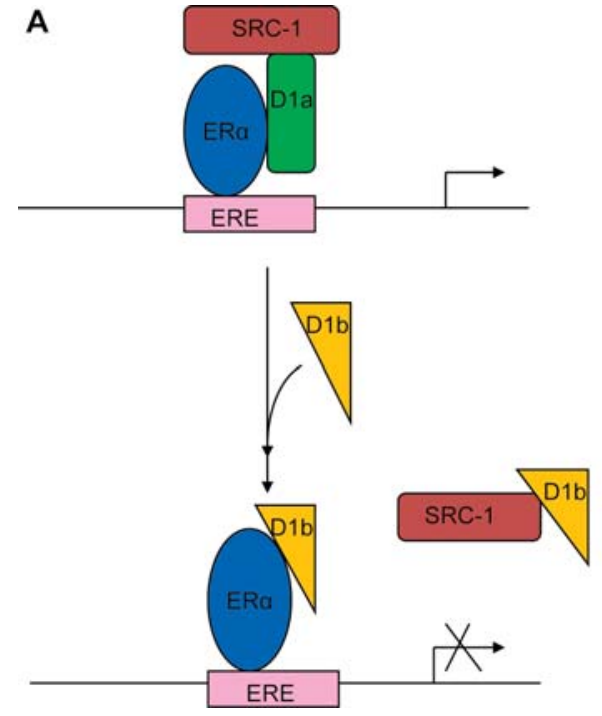

B

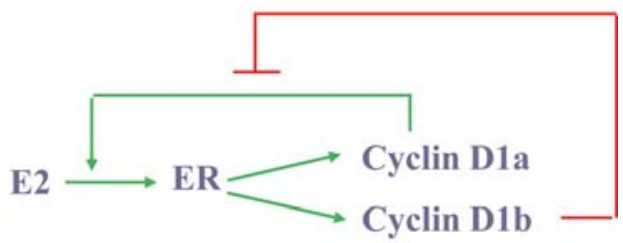

Figure 6. Hypothetical model by which cyclin D1b antagonizes cyclin D1a-induced ER $\alpha$-mediated transcription. (A) Schematic representation of a hypothetical model in which cyclin D1b is incapable of inducing ER $\alpha$-mediated transcription because it fails to recruit SRC1 to the receptor. Cyclin D1b antagonizes cyclin D1a-induced ER $\alpha$-mediated transcription by competing with cyclin D1a for ER $\alpha$ binding. (B) Hypothetical model in which cyclin D1b acts as a block on cyclin D1a and ER $\alpha$-positive feedback loop.

\section{Discussion}

Cyclin D1a has been known for years only as a cell cycle regulator facilitating the progression of the cell cycle through the G1 phase by activating the cyclin-dependent kinases (CDKs). More recently, Zwijsen et al unraveled a novel CDK-independent role for cyclin D1a and demonstrated that cyclin D1a can substitute for estrogen to activate ER $\alpha$ mediated transcription (11). Interestingly, cyclin D1 gene transcription can be directly induced by activation of $\mathrm{ER} \alpha$ (25). An estrogen-responsive element that has been found in the promoter region of the cyclin D1 gene (26). When ER $\alpha$ is activated by estrogen or agonists, it can bind to this estrogenresponsive element in the promoter region of the cyclin D1 gene. A transcription initiation complex is then recruited through SRC-1 which binds to activated ER $\alpha$ and cyclin D1 transcription is then initiated. Cyclin D1a activation of ER $\alpha$ mediated transcription and transcriptional induction of cyclin D1a by ER $\alpha$ forms a positive feedback loop, which plays a key role in inducing proliferation of estrogen responsive cells. In this study we demonstrated that cyclin D1b is incapable of inducing ER $\alpha$-mediated transcription because it fails to recruit SRC-1 to this receptor. Cyclin D1b was shown to antagonize cyclin D1a-induced ER $\alpha$-mediated transcription by competing with cyclin D1a for ER $\alpha$ binding (Fig. 6A). Cell proliferation assays showed that cyclin D1a and cyclin D1b had a differential effect on estrogen-dependent breast carcinoma cell growth with cyclin D1a stimulating the growth of ER $\alpha$-positive breast cancer T47D cell while cyclin D1b repressed the growth. These findings suggest that cyclin 
D1b acts as a block on the cyclin D1a-ER $\alpha$-positive feedback loop and negatively regulates breast epithelial cell proliferation (Fig. 6B). Disruption of this balance may result in overproliferation of breast epithelial cells.

Cyclin D1a and cyclin D1b share the first 241 amino acids, but the alternate cyclin D1b lacks the last 55 amino acids at the carboxyl terminus which are replaced by a 33 amino acid sequence. The carboxyl terminal leucine-rich LLXXXL motif at position 254-259 of cyclin D1a is very similar to the activation function domain-2 (AF-2) in ER $\alpha$ that constitutes a binding site for SRC-1. In the absence of ligand, cyclin D1a can act as a bridging factor to recruit SRC-1 to ER $\alpha$ and activate ER $\alpha$-mediated transcription (19). This motif is missing from the carboxy terminal end of cyclin D1b. Yet, despite our finding that cyclin D1b cannot recruit SRC-1 to $\mathrm{ER} \alpha$, we found that cyclin D1b could physically interact with both ER $\alpha$ and SRC-1. It has been reported, that amino acids 142-178 of cyclin D1 are required for ER $\alpha$ binding (27) and two additional LLXXXL motifs at amino acid position 137142 and 143-148 are found in both cyclin D1a and cyclin D1b which might also constitute binding sites for SRC-1. These motifs overlap with the amino acids required for ER $\alpha$ binding and this could explain why cyclin D1b can bind to both ER $\alpha$ and SRC-1, but not at the same time. The possibility that ER $\alpha$ and SRC-1 bind to cyclin D1b through overlapping domains suggests that $\mathrm{ER} \alpha$ and SRC- 1 compete for binding to cyclin D1b. Preoccupation of cyclin D1b by either SRC-1 or ER $\alpha$ is expected to prevent the other protein binding. The carboxyl terminus of cyclin D1a contains threonine 286 and 288 residues that are important for protein nuclear export and turnover (28-30). Lacking the Thr286 and Thr288 residues, cyclin D1b is refractory to CRM1dependent nuclear export, and remains constitutively nuclear (4-6). The constitutive nuclear localization makes cyclin D1b effectively antagonize the action of cyclin D1a on ER $\alpha$ mediated transcription.

Since Kong et al first reported that the cyclin D1 gene G870A polymorphism influenced the age of onset of hereditary non-polyposis colorectal cancer (31), a large number of epidemiological studies have investigated this polymorphism in cancer susceptibility. In breast cancer the CCND1 A870 allele appears to be protective in some study populations $(32,33)$. The polymorphism alters the splice donor sequence at the boundary of exon 4 and intron 4 and is thought to enhance the alternate splicing, which gives rise to a variant transcript (transcript $\mathrm{b}$ ). Yu et al reported that more transcript $b$ is produced from the A870 allele than the G870 allele in malignant breast carcinoma and benign breast lesions (34). The current finding that cyclin D1b antagonizes cyclin D1a-induced ER $\alpha$-mediated transcription suggests its involvement in negative regulation of $\mathrm{ER} \alpha$-positive breast cancer cell growth. This provides a possible explanation for the association between the CCND1 G870A polymorphism and decreased cancer risk for some types of breast cancer.

Approximately $70 \%$ of breast cancer patients are ER positive at diagonosis (35). Hormonal therapy such as tamoxifen is the first choice of treatment for these patients. Eventually breast cancer cells become estrogen-independent and resistant to hormonal therapy. It has been suggested that activation of ER $\alpha$ by cyclin D1a enables cells to bypass the requirement for estrogen and therefore provides a mechanism for estrogen-independent growth of breast tumor cells (11). Our finding that cyclin D1b negatively regulates breast cancer cell growth by antagonizing the action of cyclin D1a on ER $\alpha$ transcriptional activity raises the possibility that modified cyclin D1b could be a potential therapeutic reagent for the ER-positive breast cancer patients who are resistant to hormonal therapy.

\section{Acknowledgments}

We thank Matilde Olive for her assistance with the tissue culture experiments, Dr Nanyue Chen for his comments regarding this work and Dr Ming-Jer Tsai (Baylor College of Medicine, Houston, TX) for kindly providing ERE-TK-CAT construct. This work was supported by National Cancer Institute grant CA70759 (to Marsha L. Frazier), National Institutes of Health Cancer Center Support Grant CA 16672 (to John Mendelsohn, PI).

\section{References}

1. Arnold A, Kim HG, Gaz RD, et al: Molecular cloning and chromosomal mapping of DNA rearranged with the parathyroid hormone gene in a parathyroid adenoma. J Clin Invest 83: 2034-2040, 1989.

2. Betticher DC, Thatcher N, Altermatt HJ, Hoban P, Ryder WD and Heighway $\mathrm{J}$ : Alternate splicing produces a novel cyclin D1 transcript. Oncogene 11: 1005-1011, 1995.

3. Hosokawa Y, Gadd M, Smith AP, Koerner FC, Schmidt EV and Arnold A: Cyclin D1 (PRAD1) alternative transcript b: fulllength cDNA cloning and expression in breast cancers. Cancer Lett 113: 123-130, 1997.

4. Leveque C, Marsaud V, Renoir JM and Sola B: Alternative cyclin D1 forms a and b have different biological functions in the cell cycle of B lymphocytes. Exp Cell Res 313: 2719-2729, 2007.

5. Lu F, Gladden AB and Diehl JA: An alternatively spliced cyclin D1 isoform, cyclin D1b, is a nuclear oncogene. Cancer Res 63: 7056-7061, 2003.

6. Solomon DA, Wang Y, Fox SR, et al: Cyclin D1 splice variants. Differential effects on localization, RB phosphorylation, and cellular transformation. J Biol Chem 278: 30339-30347, 2003.

7. Coqueret O: Linking cyclins to transcriptional control. Gene 299: 35-55, 2002.

8. Opitz OG and Rustgi AK: Interaction between Sp1 and cell cycle regulatory proteins is important in transactivation of a differentiation-related gene. Cancer Res 60: 2825-2830, 2000.

9. Bienvenu F, Gascan H and Coqueret O: Cyclin D1 represses STAT3 activation through a Cdk4-independent mechanism. J Biol Chem 276: 16840-16847, 2001.

10. Inoue $\mathrm{K}$ and Sherr CJ: Gene expression and cell cycle arrest mediated by transcription factor DMP1 is antagonized by Dtype cyclins through a cyclin-dependent-kinase-independent mechanism. Mol Cell Biol 18: 1590-1600, 1998.

11. Zwijsen RM, Wientjens E, Klompmaker R, van der Sman J, Bernards R and Michalides RJ: CDK-independent activation of estrogen receptor by cyclin D1. Cell 88: 405-415, 1997.

12. Neuman E, Ladha MH, Lin N, et al: Cyclin D1 stimulation of estrogen receptor transcriptional activity independent of cdk4. Mol Cell Biol 17: 5338-5347, 1997.

13. Lamb J, Ladha MH, McMahon C, Sutherland RL and Ewen ME: Regulation of the functional interaction between cyclin D1 and the estrogen receptor. Mol Cell Biol 20: 8667-8675, 2000.

14. Knudsen KE, Cavenee WK and Arden KC: D-type cyclins complex with the androgen receptor and inhibit its transcriptional transactivation ability. Cancer Res 59: 2297-2301, 1999.

15. Petre CE, Wetherill YB, Danielsen M and Knudsen KE: Cyclin D1: mechanism and consequence of androgen receptor corepressor activity. J Biol Chem 277: 2207-2215, 2002.

16. Lin HM, Zhao L and Cheng SY: Cyclin D1 is a ligandindependent co-repressor for thyroid hormone receptors. J Biol Chem 277: 28733-28741, 2002. 
17. Reutens AT, Fu M, Wang C, et al: Cyclin D1 binds the androgen receptor and regulates hormone-dependent signaling in a p300/CBP-associated factor (P/CAF)-dependent manner. Mol Endocrinol 15: 797-811, 2001.

18. McMahon C, Suthiphongchai T, DiRenzo J and Ewen ME: $\mathrm{P} / \mathrm{CAF}$ associates with cyclin D1 and potentiates its activation of the estrogen receptor. Proc Natl Acad Sci USA 96: 5382-5387, 1999.

19. Zwijsen RM, Buckle RS, Hijmans EM, Loomans CJ and Bernards R: Ligand-independent recruitment of steroid receptor coactivators to estrogen receptor by cyclin D1. Genes Dev 12: 3488-3498, 1998.

20. Lazaro JB, Bailey PJ and Lassar AB: Cyclin D-cdk4 activity modulates the subnuclear localization and interaction of MEF2 with SRC-family coactivators during skeletal muscle differentiation. Genes Dev 16: 1792-1805, 2002.

21. Adnane J, Shao Z and Robbins PD: Cyclin D1 associates with the TBP-associated factor TAF(II)250 to regulate Sp1-mediated transcription. Oncogene 18: 239-247, 1999.

22. Klein-Hitpass L, Tsai SY, Greene GL, Clark JH, Tsai MJ and O'Malley BW: Specific binding of estrogen receptor to the estrogen response element. Mol Cell Biol 9: 43-49, 1989.

23. Graham FL and van der Eb AJ: A new technique for the assay of infectivity of human adenovirus 5 DNA. Virology 52: 456-467, 1973.

24. Meng Q, Rayala SK, Gururaj AE, Talukder AH, O'Malley BW and Kumar R: Signaling-dependent and coordinated regulation of transcription, splicing, and translation resides in a single coregulator, PCBP1. Proc Natl Acad Sci USA 104: 5866-5871, 2007.

25. Altucci L, Addeo R, Cicatiello L, et al: 17beta-Estradiol induces cyclin D1 gene transcription, p36D1-p34cdk4 complex activation and $\mathrm{p} 105 \mathrm{Rb}$ phosphorylation during mitogenic stimulation of G(1)-arrested human breast cancer cells. Oncogene 12: 2315-2324, 1996.
26. Sabbah M, Courilleau D, Mester J and Redeuilh G: Estrogen induction of the cyclin D1 promoter: involvement of a cAMP response-like element. Proc Natl Acad Sci USA 96: 11217-11222, 1999.

27. Wang C, Fan S, Li Z, et al: Cyclin D1 antagonizes BRCA1 repression of estrogen receptor alpha activity. Cancer Res 65: 6557-6567, 2005

28. Alt JR, Cleveland JL, Hannink M and Diehl JA: Phosphorylation-dependent regulation of cyclin D1 nuclear export and cyclin D1-dependent cellular transformation. Genes Dev 14: 3102-3114, 2000.

29. Takahashi-Yanaga F and Sasaguri T: GSK-3beta regulates cyclin D1 expression: A new target for chemotherapy. Cell Signal 20: 581-589, 2008.

30. Zou Y, Ewton DZ, Deng X, Mercer SE and Friedman E: Mirk/dyrk1B kinase destabilizes cyclin D1 by phosphorylation at threonine 288. J Biol Chem 279: 27790-27798, 2004.

31. Kong S, Amos CI, Luthra R, Lynch PM, Levin B and Frazier ML: Effects of cyclin D 1 polymorphism on age of onset of hereditary nonpolyposis colorectal cancer. Cancer Res 60: 249252,2000

32. Ceschi M, Sun CL, Van Den Berg D, Koh WP, Yu MC and Probst-Hensch N: The effect of cyclin D1 (CCND1) G870Apolymorphism on breast cancer risk is modified by oxidative stress among Chinese women in Singapore. Carcinogenesis 26: 1457-1464, 2005.

33. Shu XO, Moore DB, Cai Q, et al: Association of cyclin D1 genotype with breast cancer risk and survival. Cancer Epidemiol Biomarkers Prev 14: 91-97, 2005.

34. Yu CP, Yu JC, Sun CA, Tzao C, Ho JY and Yen AM: Tumor susceptibility and prognosis of breast cancer associated with the G870A polymorphism of CCND1. Breast Cancer Res Treat 107: 95-102, 2008.

35. Normanno N, Di Maio M, De Maio E, et al: Mechanisms of endocrine resistance and novel therapeutic strategies in breast cancer. Endocr Relat Cancer 12: 721-747, 2005. 